\title{
Immunohistochemical study on ADAM33 in sinonasal inverted papillomas and squamous cell carcinomas of the larynx
}

\author{
Olga Stasikowska-Kanicka ${ }^{1}$, Małgorzata Wągrowska-Danilewicz ${ }^{1}$, Marian Danilewicz²
}

${ }^{1}$ Department of Nephropathology, Medical University of Lodz, Lodz, Poland 2Department of Pathomorphology, Medical University of Lodz, Lodz, Poland

Submitted: 27 December 2013

Accepted: 5 February 2014

Arch Med Sci 2016; 12, 1: 89-94

DOI: 10.5114/aoms.2016.57583

Copyright $\odot 216$ Termedia \& Banach

\section{Abstract}

Introduction: ADAM33 protein is a member of the family of transmembrane glycoproteins composed of multidomains. Members of the ADAM family have different activities, such as proteolysis and adhesion, making them good candidates to mediate the extracellular matrix remodeling and changes in cellular adhesion that characterize certain pathologies and cancer development.

Material and methods: The immunohistochemical method was used to examine the immunoexpression of ADAM33 in 39 formalin-fixed, paraffin-embedded tissue specimens of sinonasal inverted papillomas (IP), 44 laryngeal squamous cell carcinomas (GI grade $=11$, Gll grade $=33$ ) and 14 disease-free tissue specimens as a control.

Results: The immunoexpression of ADAM33 was localized in the epithelial cells, mesenchymal cells of the vessels and infrequently in the stromal cells. The majority of the ADAM33 was localized intracellularly, although membrane immunoexpression was also noted. All epithelial and vascular staining scores were found to be significantly increased in Gl and Gll grades of laryngeal cancer compared with controls $(p<0.001)$ and IP $(p<0.001)$. No statistically significant differences were found in immunoexpression of ADAM33 between GI and GIl tumors. The immunoexpression of ADAM33 was significantly higher in IP patients than in controls $(p<0.02)$.

Conclusions: Our findings suggest that ADAM33 could potentially contribute to tumorigenesis of the laryngeal and sinonasal region.

Key words: adamalysin, sinonasal and laryngeal lesions.

\section{Introduction}

Head and neck squamous cell carcinomas (HNSCC) are the $6^{\text {th }}$ most common cancers worldwide and are responsible for 350000 deaths each year [1, 2]. The survival rate for laryngeal cancer has remained unchanged for the past 30 years [3]. While incidence rates for cancer of the hypopharynx and larynx are decreasing, a significant increase in the number of cases of cancer of the oropharynx has been observed. The standard tumor-node-metastasis (TNM) staging system is argued to be inadequate in predicting the prognosis of this cancer [4]. Head and neck malignancies are characterized by a multiphasic and multifactorial etiopathogenesis. Smoking and alcohol consumption are the most common

\author{
Corresponding author: \\ Dr. Olga Stasikowska-Kanicka \\ Department \\ of Nephropathology \\ Medical University of Lodz \\ 251 Pomorska St \\ 92-213 Lodz, Poland \\ Phone: +48 608819069 \\ Fax: +48 426790191 \\ E-mail: olga.stasikowska@ \\ umed.lodz.pl
}


risk factors for oral, oropharyngeal, and laryngeal carcinomas.

Inverted papillomas are relatively rare epithelial tumors which generate considerable interest because they have a high rate of recurrence and a tendency for malignant transformation. Inverted papilloma occurs in approximately $20 \%$ of cases associated with an invasive squamous cell carcinoma of the sinonasal region $[5,6]$. The nature and pathogenesis of inverted papilloma are still being debated. A better understanding of the molecular events involved in malignant transformation may help to classify tumors and predict treatment responses.

The ADAMs (a disintegrin and metalloprotease) family of membrane-bound enzymes belong to a large zinc-dependent superfamily called the metzincins and are found in mammals and invertebrates $[7,8]$. The ADAMs family consists of 34 members (ADAM1-ADAM34). All ADAM members are type 1 transmembrane zymogen glycoproteins that include 8 distinct domains, including a signal domain, a prodomain, a metalloproteinase domain, a disintegrin or integrin-binding domain, a cysteine-rich region, an epidermal growth factor (EGF)-like domain, a transmembrane sequence and an intracellular C-terminal end [9]. ADAMs are initially synthesized as enzymatically inactive precursor proteins. This inactive state is due to the interaction of a cystein residue in the prodomain with the zinc ion at the catalytic site. ADAMs have an active site in the metalloprotease domain, containing a zinc-binding catalytic site, like matrix metalloproteinase members $[10,11]$. Protease activity is the best-defined function of ADAMs, with most of the putative substrates currently identified being transmembrane proteins. For protease activation, the prodomain is removed by a furin-like convertase or by autocatalysis. Although all ADAMs possess the metalloproteinase domain, only about a half exhibit protease activity. The protease function of several ADAM members has been determined experimentally, including ADAM8, 9, 10, 12, 15, 17, 19, 20, 21, 28, 30 , and 33 . The disintegrin domain is found in all ADAMs. It binds to integrins, a group of adhesion proteins involved in cell adhesion, migration and cell signaling [12]. The function of the remaining domains, i.e., the cysteine-rich region, EGF-like sequence and cytoplasmic domain, remain to be determined. In some of the ADAMs, however, the cysteine region has been implicated in regulating protease activity and controlling substrate specificity [13].

Although ADAM molecules are known to be relatively long, it has recently become clear that mammalian ADAMs are involved in various biological and disease-related processes. Studies have shown that some of these proteins participate in multiple physiological processes (e.g. cell adhesion, cell migration, and the release of cell surface molecules such as cytokines and growth factors) [13-15], while others play a role in such complex events as smooth muscle development, fertilization, neurogenesis and the immune response [16, 17]. Moreover, some authors suggest that ADAMs may play a role in the promotion of tumor invasion and metastasis, via cleavage of extracellular matrix proteins or by direct modulation of tumor cell adhesion [9, 18].

ADAM33 has been linked with several respiratory and skin diseases and was especially implicated in asthma and bronchial hyperresponsiveness, as well as the autoimmune skin disease psoriasis [19, 20]. A soluble form of ADAM33 has been identified in the bronchoalveolar lavage fluid (BALF) of asthmatic patients, and its levels inversely correlate with lung function [21]. ADAM33 is selectively expressed in mesenchymal cells, and its metalloprotease activity has been linked to tissue remodeling. Moreover, ADAM-33 has been shown to promote angiogenesis, which is an important feature of carcinogenesis [22]. Although it has been reported that ADAM33 possesses catalytic activity, its specific substrate and the role in tumorigenesis are still unknown.

The aim of our study was to evaluate the immunoexpression of ADAM33 in sinonasal inverted papillomas and squamous cells carcinomas of the larynx and to determine its correlation with histological grade.

\section{Material and methods}

\section{Patients}

Thirty-nine formalin-fixed, paraffin-embedded tissue specimens of sinonasal inverted papillomas (IP), 44 laryngeal squamous cell carcinomas (GI grade $=11$, Gll grade $=33$ ) and 14 normal-looking tissue specimen (a margin of benign lesions) were retrieved from archival material (Chair of Pathomorphology, Medical University of Lodz, Poland). The age range for sinonasal inverted papillomas was from 29 to 84 years (mean \pm SD: $62.1 \pm 18.3$ ) and for laryngeal cancer was from 47 to 83 years $(61.4 \pm 9.8)$.

\section{Light microscopy}

Paraffin-embedded tissue sections taken from postoperative material were diagnosed using standard hematoxylin and eosin staining and the histological diagnoses were established according to the current standards [23]. The main criteria of tissue selection were histopathological similarities within the group and localization of lesions. 


\section{Immunohistochemistry}

Formalin-fixed, paraffin-embedded tissue sections were incubated at $56^{\circ} \mathrm{C}$ for $24 \mathrm{~h}$ and rested for $1 \mathrm{~h}$ in xylene and $15 \mathrm{~min}$ in graded alcohols for deparaffinization. Antigen retrieval was performed by boiling in Target Retrieval Solution (TRS, Low $\mathrm{pH}$, Dako, Denmark) for $30 \mathrm{~min}$ in a microwave oven $(2 \times 5 \mathrm{~min}$ at $360 \mathrm{~W}, 2 \times 5 \mathrm{~min}$ at $180 \mathrm{~W}$, $2 \times 5 \mathrm{~min}$ at $90 \mathrm{~W}$ ). Endogenous peroxidase activity was blocked by $0.3 \%$ hydrogen peroxide in methanol for $30 \mathrm{~min}$, and then sections were rinsed with Tris-buffered saline (TBS, Dako, Denmark) and incubated for $1 \mathrm{~h}$ with polyclonal rabbit anti-ADAM33 antibody (Abcam; ab39193), concentration $2 \mu \mathrm{g} / \mathrm{ml}$. After incubation with primary antibody, slides were washed with Tris-buffered saline. Afterwards EnVision+Systems-HRP (Dako, Denmark) prepared according to the instructions of the manufacturer were used. Colorimetric detection was completed with a solution of 3,3'-diaminobenzidine (Dako, Denmark). After washing, the sections were counter-stained with hematoxylin and coverslipped with Histokit.

For each sample a negative control was processed. Negative controls were carried out by incubation in the absence of the primary antibody and always yielded negative results.

The slides were examined and the level of immunoreactivity assessed. Assessment of ADAM33 staining was performed by two pathologists who were blinded to patient outcome. ADAM33 immunoexpression within areas of laryngeal squamous cell carcinoma was compared with that in the surrounding normal, healthy tissue, and the staining intensity was graded as: $0=$ negative; $1+=$ weak $; 2+=$ moderate; and $3+=$ strong. The intensity of immunostaining in the epithelial cells, endothelial and smooth muscle cells of the capillaries and interstitial inflammatory infiltrates and fibroblasts was compared with that in normal laryngeal tissue.

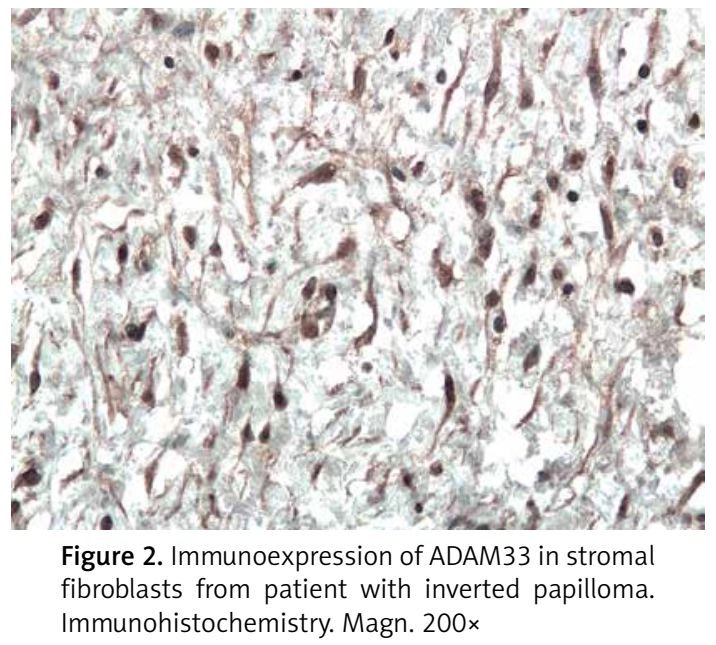

\section{Statistical analysis}

Differences between groups were tested using unpaired Student's $t$-test preceded by evaluation of normality and Levene's test. The Mann-Whitney $U$ test was used where appropriate. Results were considered statistically significant if $p<0.05$.

\section{Results}

The immunoexpression of ADAM33 was localized in the epithelial cells, in the endothelial and smooth muscle cells of the capillaries in stromal tissue surrounding neoplastic cells (Figure 1), and infrequently in the stromal cells (Figure 2). In all examined cases, ADAM33 was expressed in infiltrating inflammatory cells (Figure 3 ). Our study revealed that the majority of the ADAM 33 was localized intracellularly although membrane immunoexpression was also noted.

The results of a semiquantitative evaluation of ADAM33 protein immunoexpression are presented in Table I. All epithelial and vascular staining scores were found to be significantly increased in

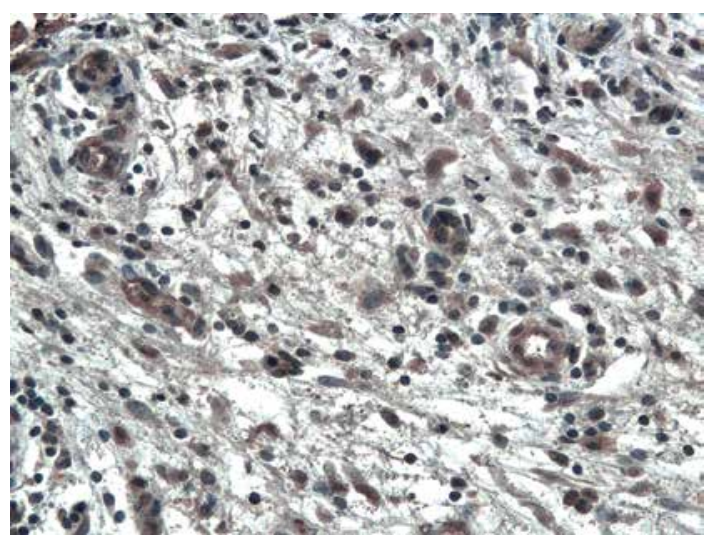

Figure 1. Immunoexpression of ADAM33 in endothelial cells and smooth muscle cells of stromal capillaries from patient with $\mathrm{Gl}$ cancer. Immunohistochemistry. Magn. 200x

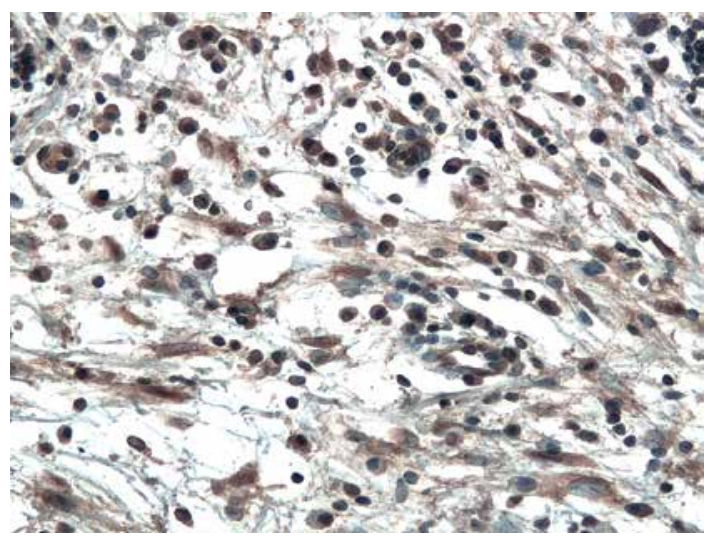

Figure 3. Cytoplasmic immunoexpression of ADAM33 in stromal inflammatory infiltrates from patient with Gll cancer. Immunohistochemistry. Magn. 200x 
Olga Stasikowska-Kanicka, Małgorzata Wągrowska-Danilewicz, Marian Danilewicz

Table I. Semiquantitative data of ADAM33 immunoexpression in inverted papillomas, carcinomas and controls

\begin{tabular}{|lccccc|}
\hline Variables & $\begin{array}{c}\text { Controls } \\
(n=14)\end{array}$ & $\begin{array}{c}\text { Inverted } \\
\text { papilloma } \\
(n=39)\end{array}$ & $\begin{array}{c}\text { Carcinoma GI } \\
(n=11)\end{array}$ & $\begin{array}{c}\text { Carcinoma GII } \\
(n=33)\end{array}$ & $P$-value \\
\hline $\begin{array}{l}\text { ADAM-33 } \\
\text { (epithelium) }\end{array}$ & $0.9 \pm 0.11$ & $0.45 \pm 0.5$ & $1.26 \pm 0.69$ & $1.42 \pm 0.74$ & $\begin{array}{l}<0.02^{1},<0.001^{2},<0.001^{3}, \\
<0.001^{4},<0.001^{5},=0.53^{6} \text { (NS) }\end{array}$ \\
\hline $\begin{array}{l}\text { DAM-33 } \\
\text { (vessels) }\end{array}$ & $0.14 \pm 0.15$ & $0.50 \pm 0.52$ & $1.37 \pm 0.73$ & $1.40 \pm 0.72$ & $\begin{array}{c}<0.02^{1},<0.001^{2},<0.001^{3}, \\
<0.001^{4},<0.001^{5},=0.53^{6} \text { (NS) }\end{array}$ \\
\hline $\begin{array}{l}\text { ADAM-33 } \\
\text { (inflammatory } \\
\text { and stromal cells) }\end{array}$ & $0.17 \pm 0.13$ & $0.67 \pm 0.42$ & $0.86 \pm 0.52$ & $0.82 \pm 0.32$ & $\begin{array}{l}<0.001^{1},<0.001^{2},<0.001^{3}, \\
=0.21(\mathrm{NS})^{4},=0.09(\mathrm{NS})^{5}, \\
=0.76(\mathrm{NS})^{6}\end{array}$ \\
\hline
\end{tabular}

Data are expressed as mean score \pm standard deviation. ${ }^{1}$ Between controls and inverted papillomas. ${ }^{2}$ Between controls and carcinomas $G l$. ${ }^{3}$ Between controls and carcinomas GII. ${ }^{4}$ Between inverted papillomas and carcinomas GI. ${ }^{5}$ Between inverted papillomas and carcinomas GII. ${ }^{6}$ Between carcinomas $G I$ and carcinomas GII.

Gl and Gll grades of laryngeal cancer (Figures 4, 5) compared with controls $(p<0.001)$ (Figure 6) and IP $(p<0.001)$. No statistically significant differences were found in immunoexpression of ADAM33 between $\mathrm{Gl}$ and Gll tumors.

The immunoexpression of ADAM33 was significantly increased in sinonasal IP patients (Figure 7) as compared to controls $(p<0.02)$.

The immunoexpression of ADAM33 in interstitial infiltrates and interstitial fibroblasts was sometimes hard to distinguish and these cells were evaluated together.

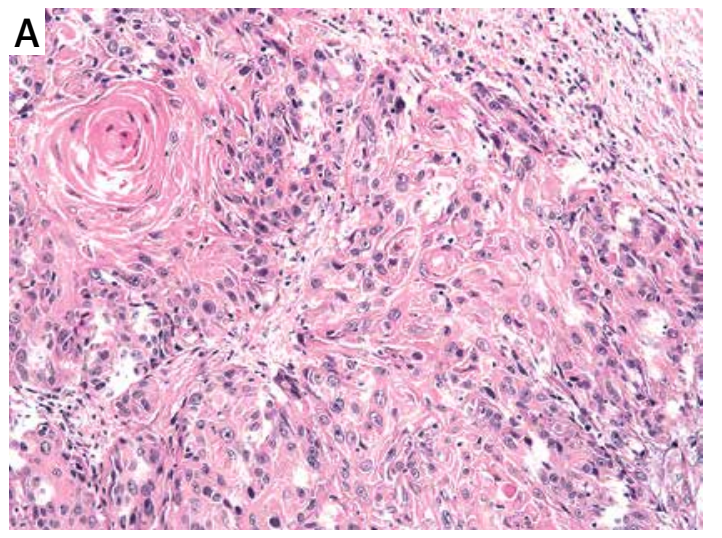

The immunoexpression of ADAM33 in infiltrating inflammatory cells and interstitial fibroblasts was significantly increased in GI and Gll grades of laryngeal cancer and IP patients as compared to controls $(p<0.001)$. However, no statistically significant differences were found in immunoexpression of ADAM33 between infiltrating inflammatory cells and interstitial fibroblasts in the studied tumors.

\section{Discussion}

Many studies have shown that members of the ADAM family play a role in fundamental biological

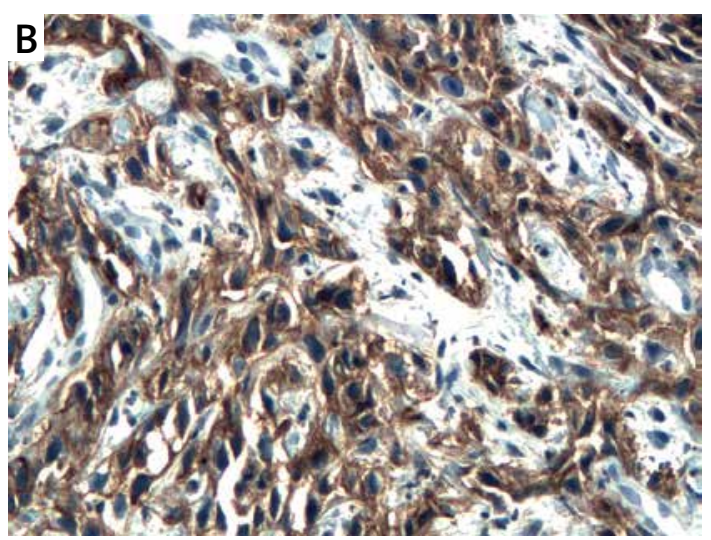

Figure 4. A - Squamous cell carcinoma GI. H + E. Magn. 100×. B - Immunoexpression of ADAM33 in squamous cell carcinoma Gl of the larynx. Immunohistochemistry. Magn. 400x
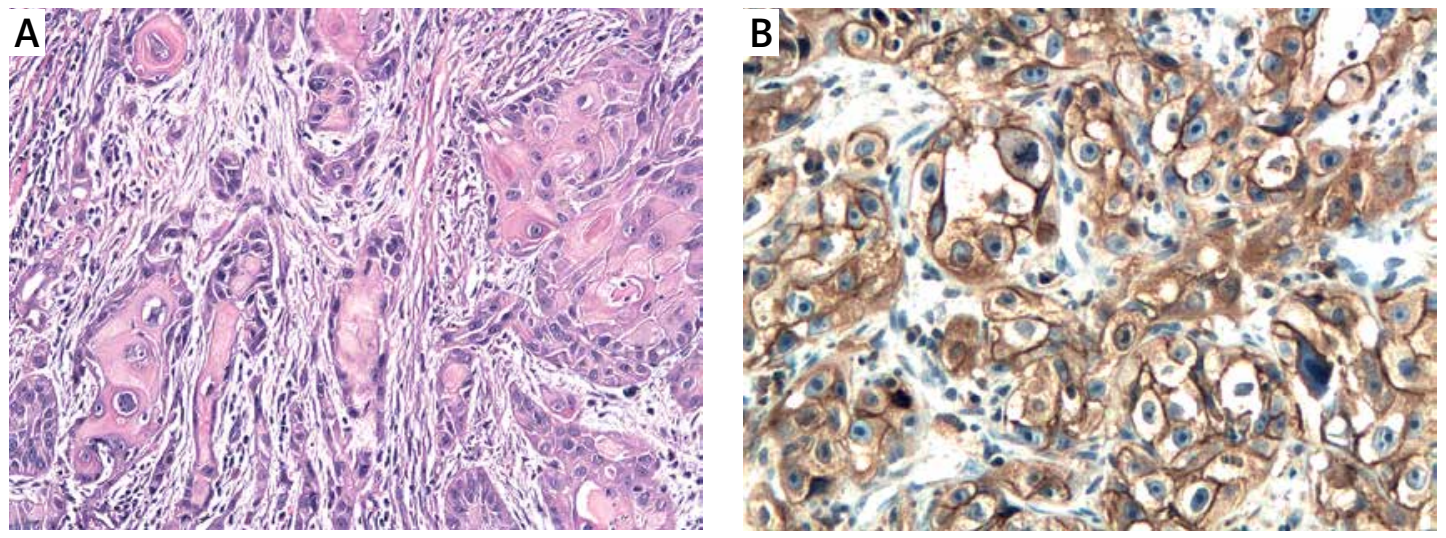

Figure 5. A - Squamous cell carcinoma GII. H + E. Magn. 100×. B - Immunoexpression of ADAM33 in squamous cell carcinoma Gll of the larynx. Immunohistochemistry. Magn. 400x 

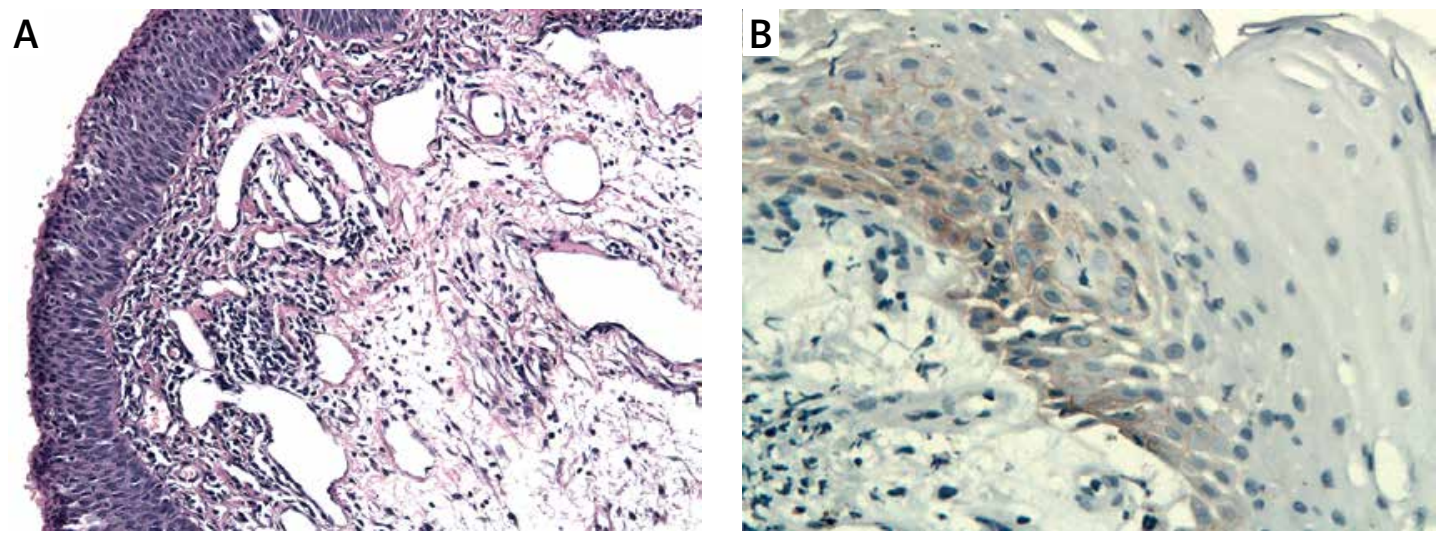

Figure 6. A - Control. H + E. Magn. 100x. B - Immunoexpression of ADAM33 in control case. Immunohistochemistry. Magn. $400 \times$
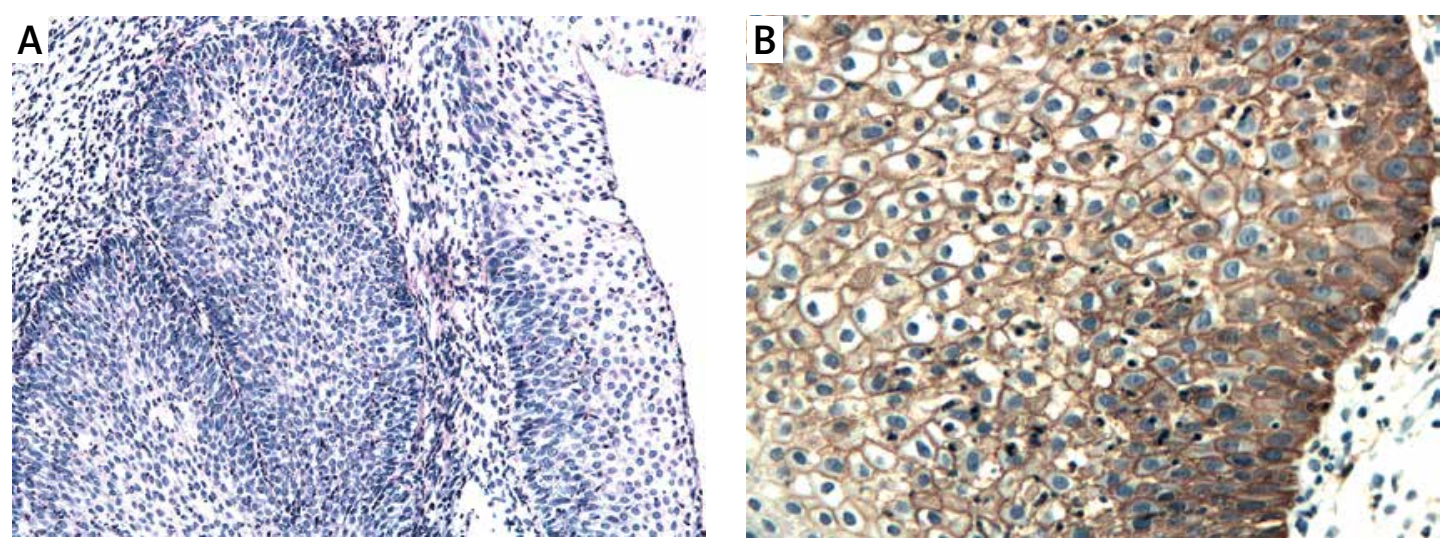

Figure 7. A - Sinonasal inverted papilloma. $\mathrm{H}+$ E. Magn. 100x. B - Immunoexpression of ADAM33 in sinonasal

inverted papilloma. Immunohistochemistry. Magn. 400x

processes ranging from cellular adhesion and migration to membrane protein shedding and proteolysis. ADAMs activity seems to be related to the control of several signaling pathways activated in cancer. For this reason, it is not surprising that deregulated expression of ADAM family members has been reported in human tumors [24]. Among ADAM family members, we focused on the newly discovered ADAM family member ADAM33. Although ADAM33 has been linked with tissue remodeling in lung diseases, its role in tumorigenesis is still largely unknown.

To our knowledge, studies concerning immunoexpression of ADAM33 in cancer are sparse. Our study revealed significantly increased immunoexpression of ADAM33 in laryngeal cancer compared with controls and IP. Moreover, the immunoexpression of ADAM33 was significantly increased in sinonasal IP in comparison with the control group. Our study did not reveal statistically significant differences in immunoexpression of ADAM33 between GI and Gll tumors.

The association of ADAM33 with cancer has been studied so far in gastric, breast and laryngeal carcinomas [25-27]. Kim et al. [25] reported that ADAM33 plays an important role in gastric cancer pathogenesis by increasing IL-18 secretion, result-

ing in higher rates of proliferation and migration. Similar to our results, Topal et al. [27] observed significantly increased immunoexpression of ADAM33 in laryngeal cancer tissue, suggesting an important role of ADAM33 in pathogenesis of this cancer. Inconsistently, Seniski et al. [26] found that the ADAM33 gene is down-regulated by selective DNA hypermethylation in breast cancer.

The expression of ADAM33 was first observed in cells of mesenchymal origin, especially fibroblasts $[20,28]$. Our results seem to be consistent with those findings. The immunoexpression of ADAM 33 was predominantly localized in the vessel and stromal mesenchymal cells. In asthma and chronic obstructive pulmonary disease Puxeddu et al. [22] found that ADAM33 was selectively expressed in mesenchymal cells, and its metalloprotease activity has been linked to tissue remodeling and angiogenesis, the latter an essential feature of carcinogenesis. The stronger mesenchymal cell immunoexpression of ADAM33 in cancer and IP found in our study may support its possible involvement in the remodeling process.

In the normal human lung, Dijkstra et al. [28] showed strong expression of ADAM33 in vascular endothelial cells, whereas other ADAM proteins were more weakly expressed. Our study revealed 
the immunoexpression of ADAM33 in vessels in all tested groups. We observed significantly increased immunoexpression of ADAM33 in cancer tissue vessels, compared with IP and controls. Similarly to our results, Topal et al. [27] also observed significant overexpression of ADAM33 in the vessels of laryngeal cancer. Puxeddu et al. [22] reported that the purified catalytic domain of ADAM33 may cause rapid induction of endothelial cell differentiation in vitro, and neovascularization ex vivo and in vivo. Based on current knowledge, it can be speculated that the distribution of ADAM33 may reflect their presumptive role in adhesion and extravasation and possibly activation of inflammatory cells. Moreover, the overexpression of ADAM33 in the vessel cells of laryngeal cancer may be associated with the angiogenic effects of this protein, possibly involved in tumor development and metastasis.

In conclusion, the present study revealed overexpression of ADAM33 in laryngeal cancer and in sinonasal IP. These findings may suggest that ADAM33 could potentially contribute to tumorigenesis of the laryngeal and sinonasal region. However, further studies are needed to better understand the molecular basis and the role of ADAM33 in HNSCC tumorigenesis.

\section{Acknowledgments}

This study was supported by the Medical University of Lodz, grant 502-03/6-038-01/502-64-022.

\section{Conflict of interest}

The authors declare no conflict of interest.

\section{References}

1. Adelstein DJ, Ridge JA, Gillison ML, et al. Head and neck squamous cell cancer and the human papillomavirus: summary of a National Cancer Institute State of the Science Meeting, November 9-10, 2008, Washington, D.C. Head Neck 2009; 31: 1393-422.

2. Parkin DM, Bray F, Ferlay J, Pisani P. Global cancer statistics, 2002. CA Cancer J Clin 2005; 55: 74-108.

3. Almadori G, Bussu F, Cadoni G, Galli J, Paludetti G, Maurizi $M$. Molecular markers in laryngeal squamous cell carcinoma: towards an integrated clinicobiological approach. Eur J Cancer 2005; 41: 683-93.

4. Wittekindt C, Wagner S, Mayer CS, Klussmann JP. Basics of tumor development and importance of human papilloma virus (HPV) for head and neck cancer. GMS Curr Top Otorhinolaryngol Head Neck Surg 2012; 11: Doc09.

5. Syrjänen KJ. HPV infection in benign and malignant sinonasal lesion. J Clin Pathol 2003; 56: 174-81.

6. Wang D, Li Y, Sun K. Nasal inverted papilloma and human papilloma virus. Lin Chuang Er Bi Yan Hou Ke Za Zhi 1998; 12: 118-9 (Abstract).

7. Rawlings ND, O'Brien E, Barratt AJ. MEROPS: the protease database. Nucleic Acids Res 2002; 30: 343-6.

8. Van Goor H, Melenhorst WB, Turner AJ, Holgate ST. Adamalysins in biology and disease. J Pathol 2009; 219 277-86.
9. Edwards DR, Handsley MH, Pennington CJ. The ADAM metalloproteinases. Mol Aspects Med 2008; 29: 258-89.

10. Becherer, JD, Blobel CP. Biochemical properties and functions of membrane-anchored metalloprotease-disintegrin proteins (ADAMs). Curr Top Dev Biol 2003; 54: 101-23.

11. Black RA, White JM. ADAMs: focus on the protease domain. Curr Opin Cell Biol 1998; 10: 654-9.

12. Stupack DG. The biology of integrins. Oncology. Williston Park 2007; 21: 6-12.

13. Reiss K, Ludwig A, Saftig P. Breaking up the tie: disintegrin-like metalloproteinases as regulators of cell migration in inflammation and invasion. Pharmacol Ther 2006; 111: 985-1006.

14. Primakoff P, Myles DG. The ADAM gene family: surface proteins with adhesion and protease activity. Trends Genet 2000; 16: 83-7.

15. Schlondorff, J, Blobel CP. Metalloprotease-disintegrins: modular proteins capable of promoting cell-cell interactions and triggering signals by protein-ectodomain shedding. J Cell Sci 1999; 112: 3603-17.

16. Peschon, JJ, Slack JL, Reddy P, et al. An essential role for ectodomain shedding in mammalian development. Science 1998; 282: 1281-4.

17. Yamamoto S, Higuchi Y, Yoshiyama K, et al. ADAM family proteins in the immune system. Immunol Today 1999; 20: 278-84.

18. Murphy G. The ADAMs: signaling scissors in the tumour microenvironment. Nat Rev Cancer 2008; 8: 929-41.

19. Deng W, Liang WB, Gao LB, et al. Association of ADAM33 polymorphisms and susceptibility to psoriasis. DNA Cell Biol 2010; 29: 435-9.

20. Van Eerdewegh P, Little RD, Dupuis J, et al. Association of the ADAM33 gene with asthma and bronchial hyperresponsiveness. Nature 2002; 418: 426-30

21. Lee JY, Park SW, Chang HK, et al. A disintegrin and metalloproteinase 33 protein in patients with asthma: relevance to airflow limitation. Am J Respir Crit Care Med 2006; 173: 729-35.

22. Puxeddu I, Pang YY, Harvey A, et al. The soluble form of a disintegrin and metalloprotease 33 promotes angiogenesis: implications for airway remodeling in asthma. J Allergy Clin Immunol 2008; 121: 1400-6.

23. Barnes L, Everson JW, Reichart P, et al. World Health Organization Classification of Tumours. Pathology and Genetics Head and Neck Tumours. IARC Press Lyon 2005; 15-7, 28-32.

24. Mochizuki S, Okada Y. ADAMs in cancer cell proliferation and progression. Cancer Sci 2007; 98: 621-8.

25. Kim KE, Song H, Hahm C, et al. Expression of ADAM33 is a novel regulatory mechanism in IL-18-secreted process in gastric cancer. J Immunol 2009; 182: 3548-55.

26. Seniski GG, Camargo AA, lerardi DF, et al. ADAM33 gene silencing by promoter hypermethylation as a molecular marker in breast invasive lobular carcinoma. BMC Cancer 2009; 9: 80.

27. Topal O, Erinanc H, Ozer C, Canpolat ET, Celik SB, Erbek SS. Expression of "a disintegrin and metalloproteinase-33" (ADAM-33) protein in laryngeal squamous cell carcinoma. J Laryngol Otol 2012; 126: 511-5.

28. Dijkstra A, Postma DS, Noordhoek JA, et al. Expression of ADAMs ("a disintegrin and metalloprotease") in the human lung. Virchows Arch 2009; 454: 441-9. 